\title{
A Numerical Investigation into the Bending of Metallic Laminate Sheet
}

\author{
Richard P. Turner \\ School of Metallurgy \& Materials, University of Birmingham, Birmingham, United Kingdom \\ Email: r.p.turner@bham.ac.uk
}

How to cite this paper: Turner, R.P. (2019) A Numerical Investigation into the Bending of Metallic Laminate Sheet. World Journal of Engineering and Technology, 7, 314-324.

https://doi.org/10.4236/wjet.2019.72022

Received: March 22, 2019

Accepted: May 5, 2019

Published: May 8, 2019

Copyright $\odot 2019$ by author(s) and Scientific Research Publishing Inc. This work is licensed under the Creative Commons Attribution International License (CC BY 4.0).

http://creativecommons.org/licenses/by/4.0/

(c) (i) Open Access

\begin{abstract}
A finite element model to simulate the bending of tri-layer laminate metallic sheet was proposed, and the model was developed in the commercial finite element (FE) solver deform. The model was simulated under adiabatic conditions (thus assuming zero heat transfer), with room temperature material properties and an ambient atmosphere assumed throughout. The models used copper as the core layer, whilst the upper and lower face layers were alternated between an aluminium alloy $\mathrm{Al} 2017$, a titanium alloy Ti-6Al-4V, and a stainless steel 316L. Thus, room temperature mechanical properties for Ti-6Al-4V, copper, 316L stainless steel and $2017 \mathrm{Al}$ alloy were entered into the model. FE predictions suggest that the material used in the face layers are of significant design importance, with variation in the peak strain in the face layers of around one-third, whilst significant variation in these layers for peak Von Mises stress, with Ti-6Al-4V and Al 2017 alloys was significantly closer to their ultimate tensile strength (UTS) values than 316L. However in the core copper layer the stress and strain predictions were largely unaffected. In models that mixed Al 2017 and 316L upper and lower face layers, significant differences in peak strains in the face layers were predicted, with the $316 \mathrm{~L}$ layer suffering greater strains when paired with the $\mathrm{Al} 2017$ alloy than paired with itself. A sensible locating of the materials in upper and lower face layers is predicted to give optimised stress and strain fields.
\end{abstract}

\section{Keywords}

Stress, Strain, Layer, Simulation, Cockroft-Latham

\section{Introduction}

Sheet metal forming processes are manufacturing methods during which an external force is applied to a minimal quantity of sheet, to modify its geometry or shape rather than to perform material removal operations [1]. The external force 
applied to the sheet causes internal stress fields within the sheet to exceed the yield strength, so inducing plastic deformation into the part. As such, the sheet may be formed into simplistic or complex components, all from the simplistic net-shape sheet prior to operation [2]. Sheet forming operations can be classified into a number of distinct processes, including drawing, rolling and spinning; however bending is perhaps the simplest to conceptualise [3].

The bending of metallic sheet to produced components for structural applications is used across numerous industries, including aerospace, automotive [4] and power generation. A bending operation is typically performed using a press brake machine, which is usually an automated machine whereby a hydraulic ram provides the forming force [5]. The press brake consists of a punch die applying the load (driven by the hydraulic ram) and a recess die allowing the sheet to form into a prescribed shape. Press brakes are commonly available in a variety of applied loads, but up to 100 tonnes is commonplace.

This process used to moderate loads will typically conserve the uniform thickness of the sheet throughout; however overly aggressive bend processes may lead to thinning at sections. Bending operations are commonly used to form reasonably simple structural load-bearing components, such as brackets or flange components, and these applied across aerospace, automotive and heavy industry [6].

Typical forming operations such as bending are applied to standard sheet metal; i.e. simple single layer, and uniform sheet made from the metal suited to the application. However, the forming of this simplistic sheet will inherently lead to the top portion of the sheet, as the bend location, being held in tension, whilst the bottom portion of sheet must be held in compression [7] (see Figure 1). The presence of the tensile and compressive stress fields are of importance, as after the applied external load is removed, the metallic sheet would undergo some elastic recovery and thus spring-back a small amount from its position when held with the punch die and recess die.

This does therefore suggests that targeting the upper or lower portion of the sheet to be in a specific material may improve the properties, given the different stress fields occurring within the sheet at the maximum bend location. This type of targeted properties approach would suggest a location-specific materials and component design, to optimise the mechanical property of the formed part. In practice, this could most efficiently be done with the use of laminate sheet, whereby the core region, upper and lower "face" regions, can be targeted for different material.

Laminated metallic sheet has been used across a small number of industrial applications in recent years, due to the benefits that laminated metal sheet offers over traditional solid sheet [8]; namely that the properties of the multi-layer laminated composite sheet can out-perform the single material sheet, by sensible pairing of the material for the different layers. In this study, the materials $316 \mathrm{~L}$ stainless steel, copper, aluminium alloy and titanium alloy Ti-6Al-4V are considered within the laminate layers of the sheet. 


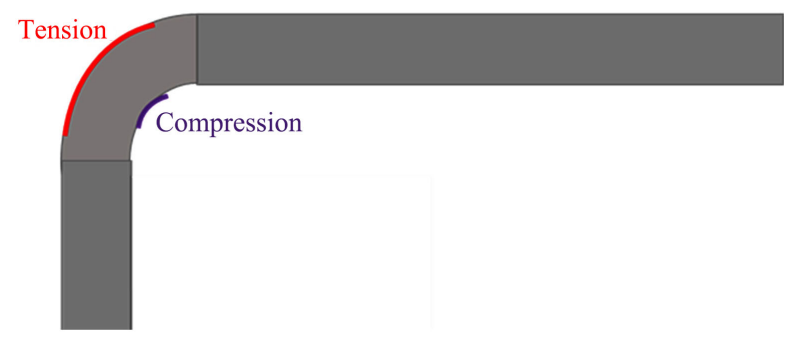

Figure 1. Simple schematic of a sheet undergoing bending, to illustrate tensile and compressive stress locations.

\section{Finite Element Modelling}

A finite element modelling framework for the bending-forming of laminate metallic sheet was developed within the commercial finite element package Deform (v11.3) [9], which is primarily a forming and forging software, but this software has been utilised for a wide range of process modelling activities. A typical bending operation would have recessed die tooling and a punch that fitted snugly around the deformed sheet. However, to explore potential variation caused by the laminate sheet and material combinations, a gap was left between the vertical sides of the recessed die and the sheet, equal to the sheet thickness.

The FE model was developed in 2D plane strain mode, to simulate the stamping of a laminate metallic sheet by representing the cross-section of the laminate sheet and the tooling within the 2D plane strain mode, and applying relevant boundary conditions, material properties and simulation controls. The workpiece was created to measure $1.8 \mathrm{~mm}$ thickness in its core region, and $0.5 \mathrm{~mm}$ thickness in its face region. The tri-layer laminate therefore has a face region either side of the core. The workpiece was set-up as such to best replicate the commercially available laminate sheets [8]. The forming operation being modelled was a relatively simple one, with a punch die applying a force to laterally displace the mid-section of the initially flat sheet, forming a bracket-type component.

The FE modelling set-up is illustrated in Figure 2. The model was performed without any heat transfer allowed between the workpiece and the atmosphere (i.e. adiabatic modelling conditions); thus the workpiece, tooling dies and atmosphere were assumed to remain at ambient temperature $\left(20^{\circ} \mathrm{C}\right)$ throughout. Modelling parameters such as the mesh density and the time-step were selected such that they were not having significant influence upon the predictions. The finite element model used $~ 1000$ elements in each laminate layer of material.

The frictional condition between the laminate layers was set to be a fully sticking condition (i.e. a Coulomb friction law with a kinetic friction coefficient of 1). Frictional conditions between the laminate layers and any tooling object in contact were fixed to a relatively low friction coefficient of 0.12 , suitable for the forging of metallic parts against tooling steel dies.

Dies were created as purely rigid objects, thus no material property need be assigned to these. As the model was purely a mechanical one, thus any thermal 
property or heat transfer could be neglected. Dies were under displacement control, with the recessed die and guide dies fixed, and the punch die moving at a speed of $1 \mathrm{~mm}$ per sec in the vertical direction. The material mechanical properties and behaviour of the deformable workpiece laminate sheet were based upon tabulated flow stress data from the literature [10] [11] [12] [13], given in Figure 3 , and room temperature mechanical properties as given in Table 1 .

A series of FE models have been simulated to consider different laminate layer combinations. These combinations are summarised in Table 2. Copper was used as the core layer for consistency, and the face layers alternated between $316 \mathrm{~L}$ stainless, Ti-6Al-4V and $\mathrm{Al} 2017$. Models 1 to 3 compare directly the case of 316L versus Ti-6Al-4V vs Al 2017 as both top and bottom face layers. Models 4 and 5 then compare the role of order, thus a top face layer of $\mathrm{Al} 2017$ and bottom of 316L versus a top face layer of $316 \mathrm{~L}$ and bottom of Al 2017. The models were processed on a single $4 \mathrm{~Gb}$ core of a computing workstation, and took approximately 20 hours to run.

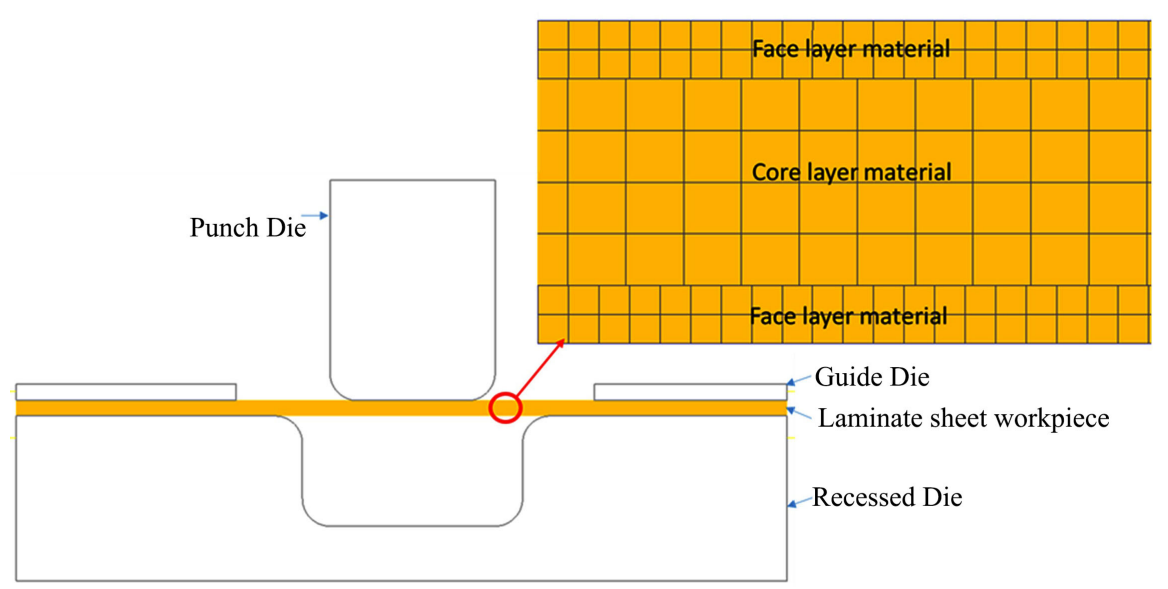

Figure 2. The FE modelling set-up for the sheet forming operation on laminate metallic sheet.

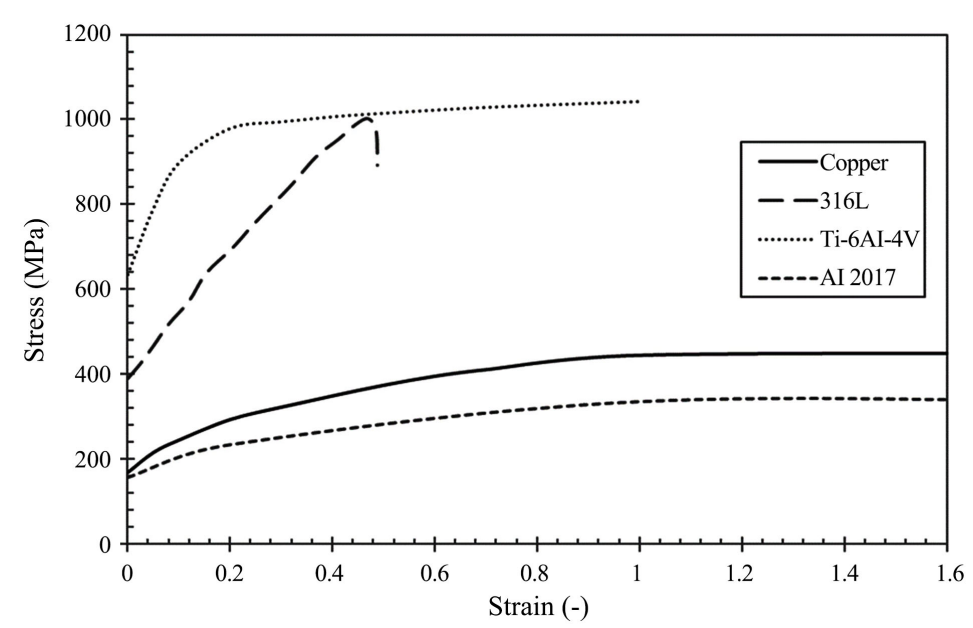

Figure 3. Stress-strain curves for the material models of use, at a fixed temperature of $20^{\circ} \mathrm{C}$, and strain rate $\sim 0.01 \mathrm{~s}^{-1}$. 
Table 1. Mechanical room temperature properties of the alloys of interest.

\begin{tabular}{ccccc}
\hline Metal & $\begin{array}{c}\text { Young's Modulus } \\
(\mathrm{GPa})\end{array}$ & $\begin{array}{c}\text { Poisson } \\
\text { ratio }(-)\end{array}$ & $\begin{array}{c}\text { Density } \\
\left(\mathbf{k g} / \mathbf{m}^{3}\right)\end{array}$ & $\begin{array}{c}\text { Ultimate strength, } \\
(\mathrm{MPa})\end{array}$ \\
\hline Ti-6Al-4V & 120 & 0.31 & 4400 & 1020 \\
$\mathrm{Al} 2017$ & 69 & 0.33 & 2800 & 280 \\
$\mathrm{Cu}$ & 117 & 0.33 & 8900 & 440 \\
316L stainless & 211 & 0.30 & 8000 & 960 \\
\hline
\end{tabular}

Table 2. Combinations of the materials used in the series of FE modelling activities.

\begin{tabular}{cccc}
\hline Material Combination & Top Face layer & Core Layer & Bottom Face Layer \\
\hline 1 & $316 \mathrm{~L}$ & Copper & $316 \mathrm{~L}$ \\
2 & $\mathrm{Ti}-6 \mathrm{Al}-4 \mathrm{~V}$ & Copper & Ti-6Al-4V \\
3 & $\mathrm{Al} 2017$ & Copper & $\mathrm{Al} 2017$ \\
4 & $\mathrm{Al} 2017$ & Copper & $316 \mathrm{~L}$ \\
5 & $316 \mathrm{~L}$ & Copper & $\mathrm{Al} 2017$ \\
\hline
\end{tabular}

\section{Results}

The five FE models were interrogated to further understand the levels of residual stress and strain within the laminate workpiece after forming. The resulting stress and strain profile maps are presented in the following results sections. A summary of the resulting stress and strain predictions are given in Table 3.

\subsection{Von Mises Effective Strain}

The predictions for the Von Mises strain left within the laminate sheet after the forming operation are given in Figure 4. For material combinations 1 to 3, where a direct comparison is made of the effect that the different facing material has, it becomes evident that the highest level of strain is present within the titanium alloy laminate. This is likely due to this material having considerably the highest flow stress value at lower strains (below approximately 0.4). However, absolute variation in peak strain is still relatively small across these three different face layer material models. The peak strain was lowest for the $316 \mathrm{~L}$ steel face layer (0.293), very close to the peak strain predicted in 2017 alloy (0.31), and even in Ti-6Al-4V it was only marginally higher, at 0.343 .

Note that the location of maximum strain in each model is similar, unsurprisingly this is located at the corner of the laminate sheet as it transitions through $90^{\circ}$ due to the punch die. Generally the peak strain experienced in each of the laminate layers occurs at the same initial vertical cross-section, which makes mathematical sense, as this location throughout the sheet would be highly strained. In some models the peak strain for the top face layer was at a different location, although this is likely just a small localised maxima at one of the other $90^{\circ}$ bends, and nothing overly concerning. 
Figure 5 illustrates the results from material combinations 4 and 5, namely the difference in the strain fields experienced in the tri-layer laminate sheet, when the position of the material in top and bottom faces is switched. Hence, the location of the high strain which was present in the top face layer of the softer aluminium alloy, in material combination 4 , switches to the bottom layer in combination 5, following the location of the aluminium alloy. Although the peak strain in the aluminium layer is roughly the same across these models, interestingly if comparing results from when the 2017 alloy was on the top face versus the bottom face, the peak strain in the core layer copper was much reduced (0.179 compared to 0.295 ) in the model with 2017 alloy as the top face, whereas the peak strain in the $316 \mathrm{~L}$ stainless steel face layer was much reduced $(0.172$ compared to 0.243 ) when the 2017 alloy was the bottom face layer. Thus, assuming the core material is the more important structural layer, then it is beneficial to have the weaker material as the top layer in a forging scenario.

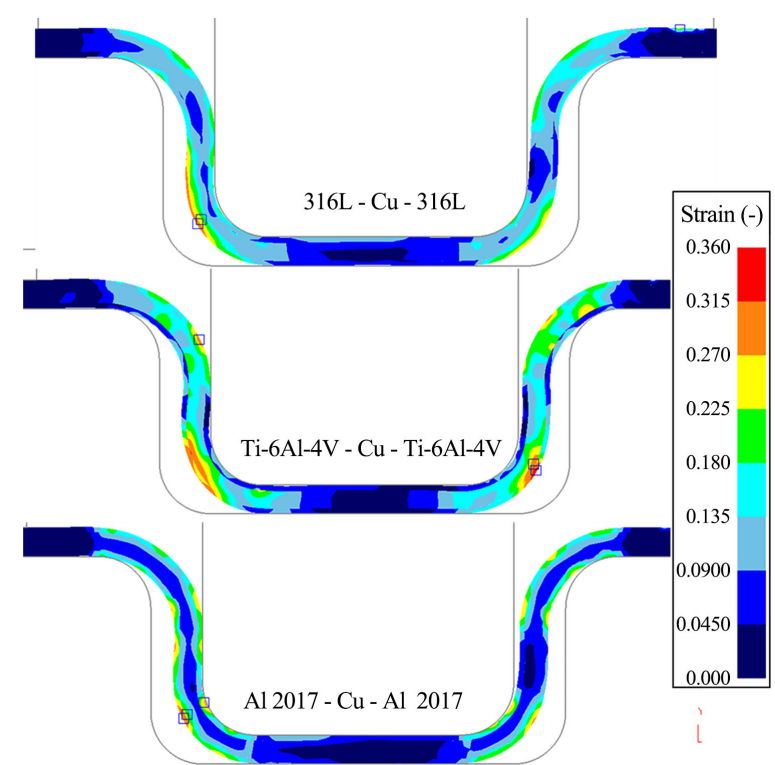

Figure 4. Predicted plastic strain field within the laminate sheet after bending, for a) Material combination 1, b) combination 2, c) combination 3.

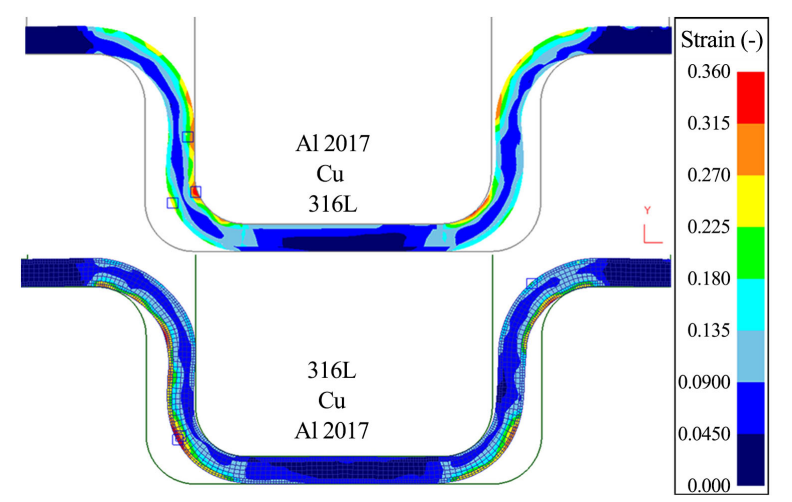

Figure 5. Predicted plastic strain field within the laminate sheet after bending, for a) Material combination 4, b) combination 5 . 
Table 3. Predicted peak stress, strain and C\&L normalised damage values within the series of FE models, in each layer of laminate.

\begin{tabular}{ccccccccccc}
\hline & \multicolumn{3}{c}{ Top Face Layer } & \multicolumn{3}{c}{ Core Layer } & \multicolumn{3}{c}{ Bottom Face Layer } \\
\cline { 2 - 11 } $\begin{array}{c}\text { Material } \\
\text { combination }\end{array}$ & $\begin{array}{c}\text { Peak } \\
\text { Stress } \\
(\mathrm{MPa})\end{array}$ & $\begin{array}{c}\text { Peak } \\
\text { Strain } \\
(-)\end{array}$ & Damage & $\begin{array}{c}\text { Peak } \\
\text { Stress } \\
(\mathrm{MPa})\end{array}$ & $\begin{array}{c}\text { Peak } \\
\text { Strain } \\
(-)\end{array}$ & Damage & $\begin{array}{c}\text { Peak } \\
\text { Stress } \\
(\mathrm{MPa})\end{array}$ & $\begin{array}{c}\text { Peak } \\
\text { Strain } \\
(-)\end{array}$ & Damage \\
\hline 1 & 796 & 0.212 & 0.256 & 240 & 0.261 & 0.218 & 867 & 0.293 & 0.342 \\
2 & 1070 & 0.275 & 0.313 & 283 & 0.286 & 0.231 & 1070 & 0.343 & 0.394 \\
3 & 245 & 0.285 & 0.298 & 232 & 0.278 & 0.207 & 249 & 0.310 & 0.355 \\
4 & 247 & 0.365 & 0.302 & 236 & 0.179 & 0.221 & 766 & 0.243 & 0.331 \\
5 & 744 & 0.172 & 0.215 & 243 & 0.295 & 0.277 & 250 & 0.35 & 0.402 \\
\hline
\end{tabular}

\subsection{Von Mises Residual Stress}

The predicted effective (Von Mises) residual stress field was similarly interrogated for the series of laminate metallic sheet forming models, and the resulting stress fields for material combinations 1 to 3 , to analyse the effect that the selection of face layer material has upon the stress distribution, are presented in Figure 6. The predicted values of stress within the protected core material remain similar across the 5 material combinations, with peak stresses typically around the 230 - $240 \mathrm{MPa}$ level. There is a small concentration of fractionally higher residual stress in the core layer when the face material is Ti-6Al-4V which peaks at $283 \mathrm{MPa}$, but is still not exceeding the flow stress of the copper material.

However, Figure 6 displays absolute values of the residual stresses within the laminate sheet. It can be seen from the material properties that for the aluminium alloy 2017, which has a much lower ultimate tensile strength than the 316L stainless or the titanium alloy, the low stresses in 2017 may actually be more of a structural issue than higher stresses in the stronger materials. Thus, Figure 7 displays the residual stress fields predicted in the material combinations 1 to 3 , but normalised against each model's face material ultimate tensile strength (UTS) value. Whilst the titanium alloy is still the material most likely to fail due to residual stresses present exceeding the UTS, the aluminium alloy $\mathrm{Al} 2017$ is now evidently experiencing peak residual stress values closer to its UTS than the $316 \mathrm{~L}$ stainless is.

Lastly, the material combinations 4 and 5 were interrogated for the change in residual stress fields if the face materials $\mathrm{Al} 2017$ and 316L switched locations (Figure 8). As with the strain fields, it is evident that the stress fields again are inherently linked with the material they correspond to. Thus, the high residual stresses within the $316 \mathrm{~L}$ bottom face layer in combination 4 are relocating to the top layer in combination 5 . There is no discernible differences in the peak stresses in the 316L layer between combinations 4 and 5 (744 MPa and $766 \mathrm{MPa})$, and similarly no discernible difference in peak stresses within the $\mathrm{Al} 2017$ layer between the combinations 4 and 5 (247 MPa and $250 \mathrm{MPa}$ ). 


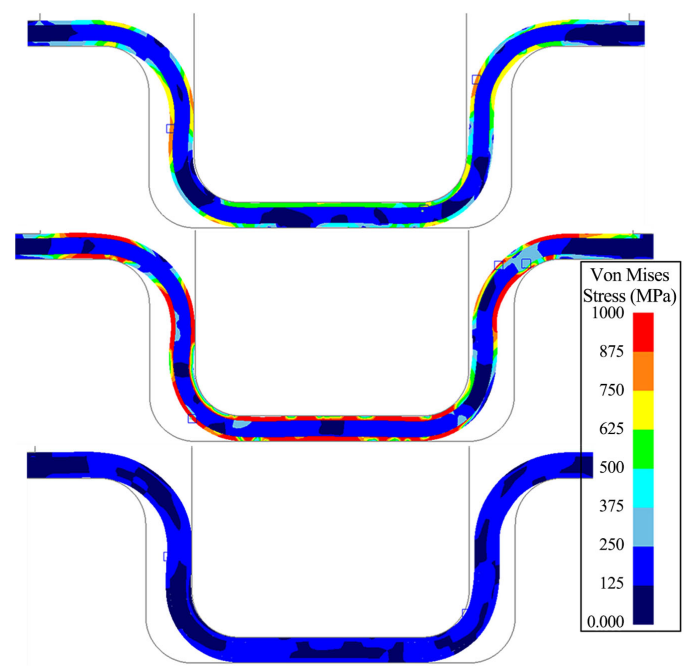

Figure 6. Predicted Von Mises stress field within the laminate sheet after bending, for a) Material combination 1, b) combination 2, c) combination 3.

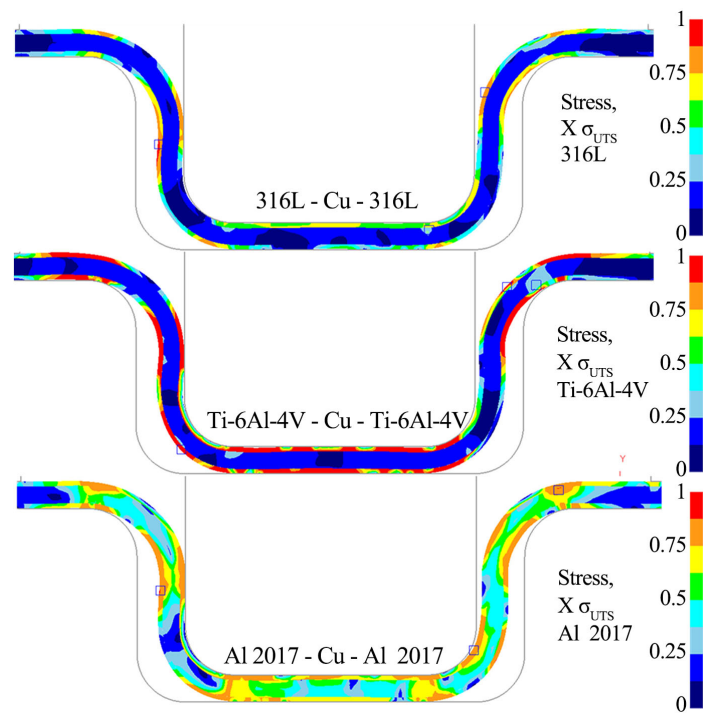

Figure 7. Predicted Von Mises stress field within laminate sheets after bending, normalised against the UTS of the face layer material, for a) combination $1, \mathrm{~b}$ ) combination $2, \mathrm{c}$ ) combination 3 .

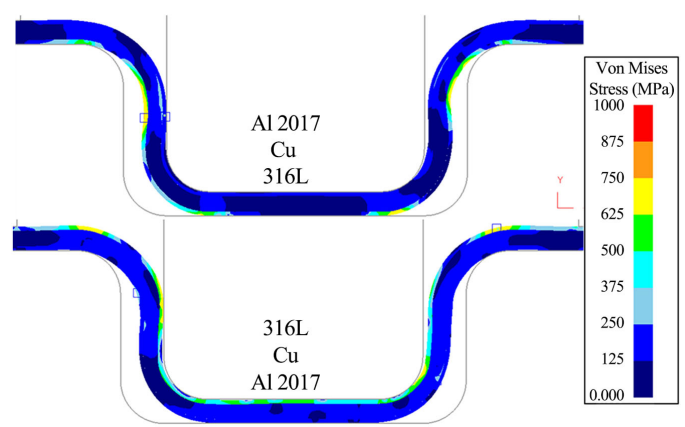

Figure 8. Predicted Von Mises stress field within the laminate sheet after bending, for a) combination 4 , b) combination 5 . 


\subsection{Damage Criterion}

A damage criterion was applied to the metallic laminate models, to provide a quantitative measure of the likelihood of cracking or other mechanical failure of one or more of the layers within the laminate sheet. The Cockroft and Latham normalised damage parameter is described by Equation (1) [14]. The equation is expressed in its functional form;

$$
C_{N}=\int_{0}^{\varepsilon f} \frac{\sigma \max (T, \varepsilon p l)}{\sigma e f f(T, \varepsilon p l)} d \overline{\varepsilon p l}
$$

where the integral ranges between a strain of zero and $\varepsilon_{f}$ the failure strain, $\sigma \max$ is the maximum principal stress (and is a function of the temperature and the plastic strain), $\sigma e f f$ is the effective (Von Mises) stress (which also is a function of the temperature and the plastic strain), and $\overline{\varepsilon_{p l}}$ is the effective plastic strain. In practice this term gives the normalised "area" beneath the stress-strain curve over the relevant strain range. Figure 9 highlights the predicted results of this damage parameter for the 5 laminate sheet forming models considered.

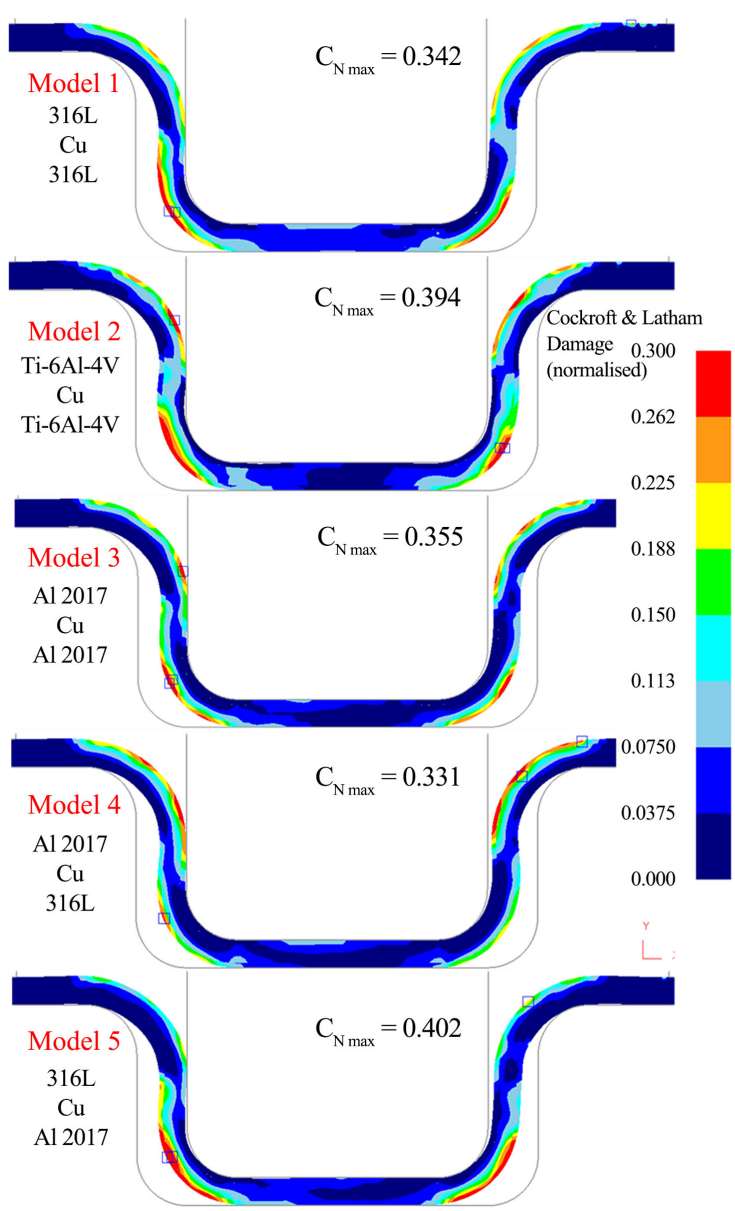

Figure 9. Predicted normalised C\&L damage within the laminate sheet after bending, for a) combination 1, b) combination 2, c) combination 3, d) combination 4, e) combination 5 . 
As the damage criterion is considering both high stress and high strain as factors that contribute to damage, it is unsurprising that the predicted field is close to that of the stress and strain distributions. The peak damage value predicted to be experienced in the laminate sheet during forming for the $\mathrm{Ti}$ alloy, $\mathrm{Al}$ alloy and steel face layer models showed only very small sensitivity to the different material combinations used, varying from 0.342 to 0.394 , with the Ti alloy seeing highest damage values. Damage always accumulates most in the face layers, as these are shown in previous figures to experience higher levels of strain and residual stresses.

Note that the peak damage criterion across all models is at a minimum of 0.331 in combination 4 (with a mixed face layer material of $\mathrm{Al} 2017$ on the top surface, and $316 \mathrm{~L}$ on the bottom), whereas it was a maximum of 0.402 in combination 5, also a mixed face layer model (with $316 \mathrm{~L}$ on the top surface, and $\mathrm{Al}$ 2017 on the bottom). This would strongly hint at the importance of using sensible face layer material in sensible locations, as these modelling predictions are suggesting this could maximise or minimise damage accumulation.

\section{Conclusions}

A finite element modelling framework for the bending of laminate sheet metal had been presented. The core layer was maintained as the copper material throughout, whilst face layers were combinations of Ti-6Al-4V, 316L stainless and $\mathrm{Al} 2017$ aluminium alloy. Based upon the predictions from the series of models, the following conclusions are drawn from this work.

- Von Mises stress and plastic strain within the core (copper) layer was largely unaffected by the material used in face layers. However, in the face layers, the Ti-6Al-4V experienced peak stresses of a relatively high fraction ( $\sim 0.9$ to 0.95) of its UTS, whereas peak stresses in the $316 \mathrm{~L}$ and $\mathrm{Al} 2017$ were at a lower fraction $(\sim 0.75)$ of these materials' UTS values.

- Regions of high strain tend to form in a particular material more preferentially than a location of the process. Hence, by switching material in the face layers, location of maximum strain can be changed from upper to lower face.

- The Cockroft and Latham normalised damage parameter, which illustrates likelihood for cracking, can be maximised or minimised by simply alternating the order of the material in the upper and lower face.

\section{Conflicts of Interest}

The author declares no conflicts of interest regarding the publication of this paper.

\section{References}

[1] Li, M.Z., Han, Q.G., Cai, Z.Y., Lui, C.G. and Su, S.Z. (2014) Multipoint Forming. Comprehensive Materials Processing, 3, 107-147. https://doi.org/10.1016/B978-0-08-096532-1.00309-5

[2] Sousa, R. (2016) Incremental Sheet Forming Technologies. Reference Module in 
Materials Science and Materials Engineering. Elsevier, Amsterdam. https://doi.org/10.1016/B978-0-12-803581-8.04055-8

[3] Ramesani, M. and Ripin, Z. (2012) Introduction to Sheet Metal Forming Processes. In: Ramezani, M. and Ripin, Z.M., Eds., Rubber-Pad Forming Processes-Technology and Applications, Elsevier, Amsterdam, 1-22. https://doi.org/10.1533/9780857095497.1

[4] Kacar, I. and Ozturk, F. (2014) Role-Forming Applications for Automotive Industry. Automotive Technology Congress, Bursa, 26-27 May 2014, 1-5.

[5] Fournier, R. and Fournier, S. (1989) Sheet Metal Handbook. H.P. Books, Los Angeles, CA, 37.

[6] Fallahiarezoodar, A. and Altan, T. (2016) Light-Weighting in the Automotive Industry Using Sheet Metal Forming. Stamping Journal, Jan/Feb 2016, 12-14.

[7] Laws, V. (1981) Derivation of Tensile Stress-Strain Curve from Bending Data. Journal of Materials Science, 16, 1299-1304. https://doi.org/10.1007/BF01033845

[8] Vacuum Process Engineering Inc., Sacramento. http://vpei.com/laminated-clad-metal-sheet

[9] Scientific Forming Technologies Corporation (SFTC), Columbus.

[10] Li, K. and Peng, J. (2017) Mechanical Behaviour of 316L Stainless Steel after Strain Hardening. MATEC Web of Conferences, 114, Article ID: 02003. https://doi.org/10.1051/matecconf/201711402003

[11] Wojtaszek, M., Sledoba, T., Czulak, A., Weber, G. and Huffenbach, W.A. (2013) Quasi-Static and Dynamic Tensile Properties of Ti-6Al-4V Alloy. Archives of Metallurgy and Materials, 58, 1261-1265. https://doi.org/10.2478/amm-2013-0145

[12] Bailey, J.A., Haas, S.L. and Shah, M.K. (1972) Effect of Strain Rate and Temperature on the Resistance to Torsional Deformation of Aluminium Alloys. International Journal of Mechanical Sciences, 14, 735-754. https://doi.org/10.1016/0020-7403(72)90012-4

[13] Zapara, M., Mueller, W., Tutyshkin, N. and Wille, R. (2012) A Study of Ductile Damage and Failure of Pure Copper-Part II: Analysis of the Deep Drawing Process of a Cylindrical Shell. Technische Mechanik, 32, 631-648.

[14] Gontarz, A. and Piesiak, J. (2015) Determining the Normalized Cockroft-Latham Criterion for $\mathrm{Ti}_{6} \mathrm{Al}_{4} \mathrm{~V}$ in Tensile Testing at Room Temperature. Proceedings of the World Congress on Mechanical, Chemical, and Material Engineering, Barcelona, 20-21 July 2015, Paper No. 248. 